\title{
OVERVIEW OF UWB LOW-PROFILE PLANAR ANTENNAS
}

\author{
Ján SCHNEIDER, Ján GAMEC \\ Department of Electronics and Multimedia Communications, Faculty of Electrical Engineering and Informatics, \\ Technical University of Košice, Letná 9, 04200 Košice, Slovak Republic, \\ e-mail: jan.schneider@tuke.sk, jan.gamec@tuke.sk
}

\begin{abstract}
Historical overview of evolution wideband antennas and some practical realizations of UWB antennas are presented. Practical realization of antennas are made by LTCC technology mostly, PCB technology or their combinations. Main features of antennas such as wide frequency bandwidth, high gain and the smallest dimensions as possible are described. The features should be helpful for future research of described antennas suitable for UWB radar applications.
\end{abstract}

Keywords: low-profile antenna, UWB (ultra wideband), UWB radar, LTCC (low temperature co-fired ceramic)

\section{INTRODUCTION}

This article discusses the categorization of approaches in solving low-profile antennas for applications, which use ultra-wideband (UWB). Ultra wideband is a communication technology in which its transmission occupies a bandwidth of more than $20 \%$ of its center frequency $(>500 \mathrm{MHz})$. Antenna is one of the most important components in UWB systems. Ideally, the UWB antenna should be compact, planar and low cost [1].

In early 1940's there was examined one of the first wideband antennas structure. Firstly, Stratton and Chu [2] presented spheroidal antenna (1941), Schelkunoff proposed a biconical antenna (1943) which can be explained with Maxwell's equations [3]. The main idea of biconical geometry was used in new types of quasi biconical configuration for low-profile antennas such as Bow-tie antenna. And more, Staff of U.S. Radio Research Laboratory at Hardvard University proposed concept of several wideband antennas such as the teardrop antenna, sleeve antenna or inverted trapezoidal antenna (1947) [4]. Next, earliest spiral antenna published by J. D. Dyson (1959) belongs to the class of planar frequency independent antennas [5]. To the most recent frequency independent antenna was assigning the sinuous antenna invented by R. H. Duhamel (1982) [6]. And not to forget the microstrip (patch) antenna, it does not belong to wideband antennas, but uses different patterns. Microstrip antenna was described by Byron (1970) [7].

This overview presents approach to solutions of lowprofile planar antennas and classification of some interest UWB antennas with good features by production technology. The conclusion evaluates some realizations of UWB antennas numerically and in tabular form.

\section{CATEGORIZATION OF APPROACHES IN SOLVING LOW-PROFILE PLANAR ANTENNAS}

The first basic wideband antenna structure is spheroidal antenna. It has been evolved from a sphere to thin spheroidal wire dipole as shown in Fig. 1(a,b,c). The zero reactance occurs when the antenna length is slightly less than a half of the wavelength. This works for long thin wires. However, it is not the same for bigger wires. The zero reactance may occur when the antenna length is greater than a half of the wavelength. For a spherical conductor, there is no place at which input impedance is zero; there is always a capacitive component. Fatter antenna makes the impedance curve broader. Thus, it provides wider bandwidth [2].

Based on the fact that thicker wire provides wider impedance bandwidth than for a thin wire dipole antenna there was proposed a biconical antenna. It is formed by two infinite conical conducting end-to-end surfaces and with the finite gap at the feed point. The input impedance of infinite biconical antenna is real, because there is only a pure traveling wave. From practical aspect, biconical antenna is made of two cones finite length shown in Fig. 1d. The reactive part of input impedance is achieved by the transmission bandwidth of increasing the angle $\theta$. At the same time, real part of input impedance becomes less sensitive to changes in the frequency [3]. From theory of biconical antenna/geometry a new kind of planar lowprofile wide band antenna was developed - called Bow-tie antenna.

The frequency sensitivity of input impedance of Bowtie antenna is much greater than the sensitivity of input impedance of biconical antenna. Antenna is depicted in Fig. 1e. Frequency bandwidth in terms of impedance of Bow-tie is smaller than biconical because the surface currents are abruptly terminated at the discontinuities (base of the triangular). The antenna bandwidth is limited. The advantages of Bow-tie antennas are conformal designs with less weight and low cost 


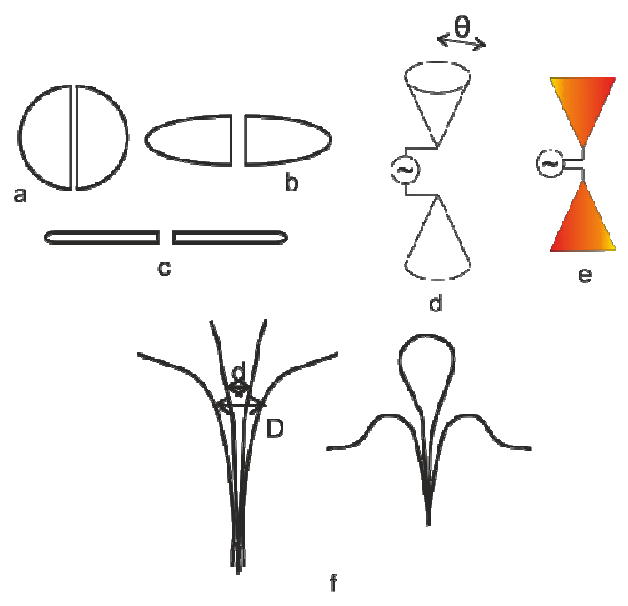

Fig. 1 Transition from 3D sphere to thin 3D spheroidal wire dipole (a,b,c), biconical antenna (d), bow-tie antenna (e), two forms of teardrop antenna (f)

The main idea of Teardrop antenna may be defined as a structure associated with the region of the transition between a guided wave and a free space or vice versa. Antenna gradually diverges from the transmission line while keeping the inner and outer conductors ratio constant. The concept of the teardrop antenna was employed in television antenna.

Antenna formed from a spiraled two-wire transmission line, which gradually transform itself into radiating structure, are called spiral antenna (Fig. 2a). This antenna belongs to the class of planar frequency of independent antennas. The arbitrary scaling of the antenna is transformed into a structure that is identical to the original structure including the possible rotation around the intersection point. Properties of antenna will be independent from frequency and antenna satisfies the angle condition. The form of the antenna can only entirely be specified by angles (not by particular dimensions). Planar spiral antennas are popular for the radiation of broadband circular polarization and have 10:1 bandwidth in low-profile geometry [5].

The sinuous antenna is the most recent frequency independent antenna (Fig. 2b). The advantages of sinuous antenna are wide bandwidth and dual-linear or dualcircular polarization at low-profile geometry. It is more complicated antenna with multi-arc geometry than spiral antenna described above. The sinuous antenna has a four arm self-complementary structure. The antenna is fed by balanced manner. Its diameter is about 0.4 wavelengths at lowest operating frequency [6].

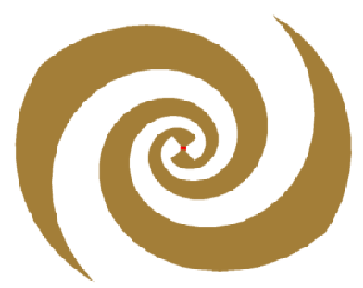

a

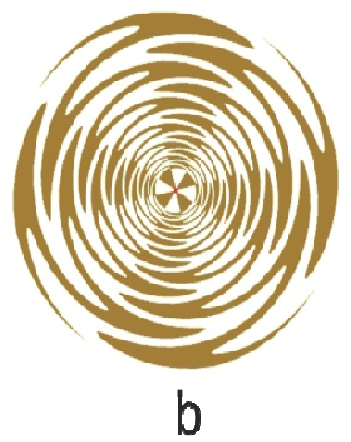

Fig. 2 Two arms spiral antenna (a), sinuous antenna (b)
The last mentioned antenna is a microstrip (patch) antenna. It is described such as a conducting strip radiator separated from ground plane by dielectric substrate shown in Fig. 3. Patch is a half of the wavelength wide and several wavelengths long. Patch is fed by coaxial connection or others planar variants of feeding. The development of microstrip antennas (used as low profile mounted antennas on rockets and missiles) showed that this was a practical concept for usage in many antenna problems. Thereby, this gave birth to a new antenna industry. Antenna has become much more widely known and used in variety of communication systems. The elementary structure of patch antenna consists of: the lower conductor (functions as a ground plane), and the upper conductor, which is a simple resonant rectangular or other geometrically shaped patch or monolithically printed array of patches. This structure is associated with a feed network. Patch has been developed for usage from $400 \mathrm{MHz}$ to $38 \mathrm{GHz}$, but at this time its usage is practically unlimited.

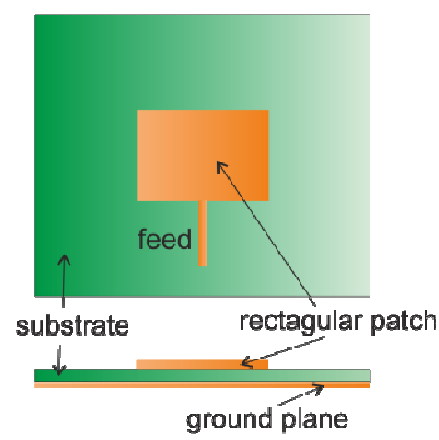

Fig. 3 Patch antenna with rectangular shape

A special category is a form of space-filling antennas that follow fractal shapes. For small antennas, spacefilling curves are used to form a long curve within a small "surface" area (structure can be resonant at wavelengths even if their structure is a fraction of wavelength). Geometry of fractals is generated in an iterative fashion [8].

\section{UWB ANTENNAS DIVIDED BY USAGE DIELECTRIC SUBSTRATE}

In chapter 4, there are specified some practical realizations of antennas, which are divided by the types of dielectric substrates. The important fact is that the dielectric substrates lead to miniaturization. Its important features are dielectric constant (permittivity) and thickness. A popular substrates are fiberglass material with epoxy resin binder $(\varepsilon r \approx 4.5)$, PTFE (polytetrafluorethylene) woven glass $(\varepsilon r \approx 2.2)$ and LTCC (low temperature co-fired ceramic) $(\varepsilon r \approx 7.8)$. Main benefits of LTCC technology are flexibility, ability to create multilayer and 3-dimensional hybrid structures. Moreover, it especially is beneficial for RF and highfrequency applications.

The resonant frequency of narrow band patches is sensitive to variations of material thickness and dielectric constant. It is important to have a material that is manufactured with proper quality control over material 
uniformity (especially er), which has a low loss and a selection of thicknesses [9].

\section{PRACTICAL REALIZATIONS}

Antennas described below are in order: 4.1, 4.2, 4.3 are antennas made by LTCC; 4.4 is antenna made by combination of LTCC and PCB; 4.5 is antenna made by only PCB technology.

\subsection{Monopole-like slot UWB antenna on LTCC}

Ground plane with slot of proposed antenna is printed on one side of LTCC substrate. Microstrip line through a fork-shaped feeding structure is printed on other side of LTCC and symmetrically positioned with respect to the centreline of the slot. The antenna is depicted in Fig. . Dimensions of antenna are $25 \times 25 \times 0.58 \mathrm{~mm}$. Bandwidth is from 3 to $11.9 \mathrm{GHz}$. Antenna was designed for UWB applications and has good impedance matching, stable radiation pattern and constant group delay over operating frequency band. The gain of the antenna is $4 \mathrm{dBi}$. The antenna has omnidirectional radiation pattern [10].

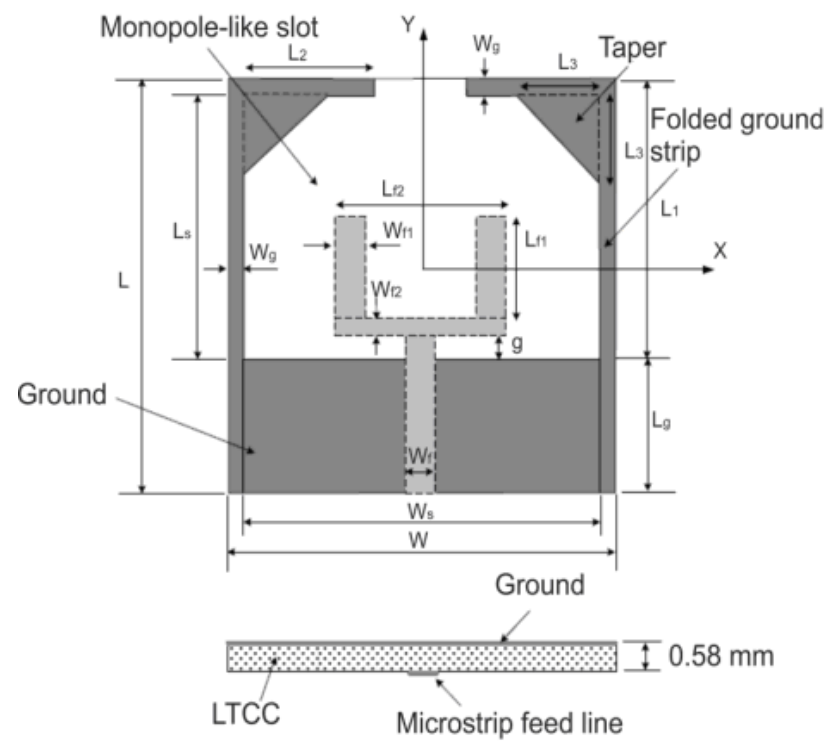

Fig. 4 Monopole-like slot antenna

\subsection{Multilayer UWB monopole antenna}

Antenna consists of two layers LTCC substrate. On each one is open rectangular loop. Loops are connected to microstrip feed line by two paths. In Fig. is depicted structure of radiation patch, ground plane and their interconnection by vias. Antenna combines two narrow band radiation elements into one broadband radiation antenna. Main purpose of proposed antenna is to achieve an extreme wide operating bandwidth from 3.6 to 10.6 $\mathrm{GHz}$ with average gain $1.45 \mathrm{dBi}$. Antenna radiation pattern can almost remain constant at a low frequency bandwidth and antenna has little distortion at higher frequencies. Multilayer antenna structure offers a miniaturized size with dimensions 20.748x11.091x1.14 $\mathrm{mm}$. Embedded feeding network is suitable for integrating with other LTCC circuits [11].

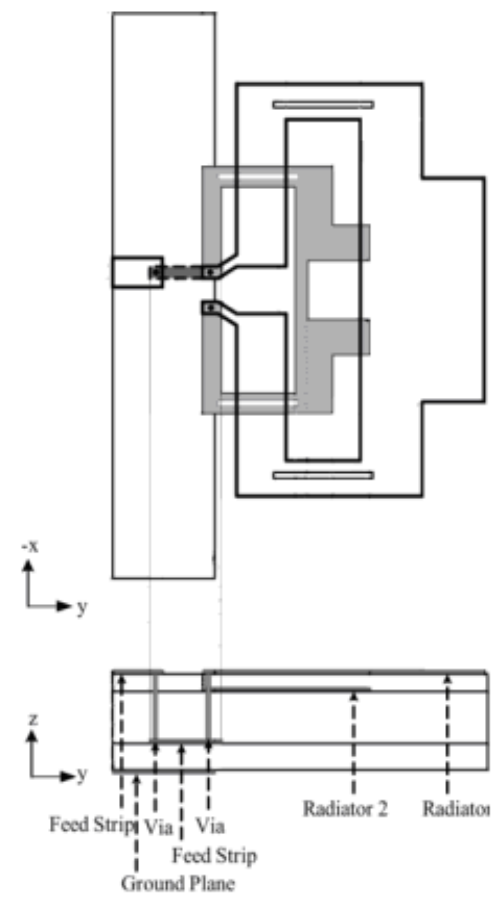

Fig. 5 Chip antenna for UWB radios

\subsection{Chip antenna for UWB radios}

In this case, radiation patch and small ground plane of proposed antenna is on one side of LTCC substrate. Chip antenna operates from 3.75 to $10.45 \mathrm{GHz}$ and has gain from -2 to $2.3 \mathrm{dBi}$ over this frequency band. Dimensions of whole proposed antenna are $17 \times 8 \times 0.8 \mathrm{~mm}$ and it's shown in Fig. . This design provides relatively constant group delay over the whole UWB frequency range. The magnitude of the transmission scattering parameter is relatively flat. The antenna has good performance and can be produced in large amounts with using single layer LTCC technology. Performance of chip antenna can be easily adjusted even after has been antenna manufactured and assembled [12].

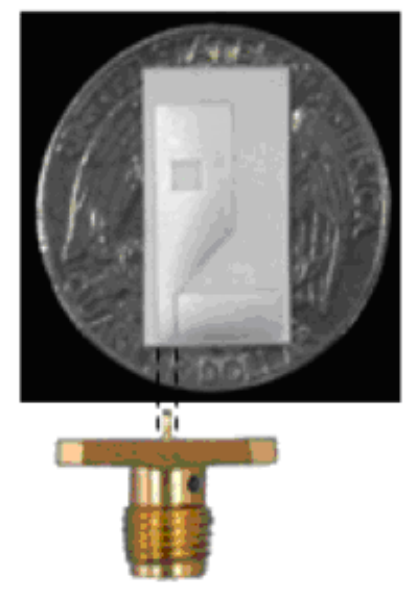

Fig. 6 Multilayer UWB monopole antenna 


\subsection{UWB chip antenna for mobile applications}

Small chip antenna with dimensions $10 \times 14 \times 1.4 \mathrm{~mm}$ is consisting of 19 layers of LTCC substrate. Each layer is $0.0762 \mathrm{~mm}$ height. There is mounted on FR4 substrate with ground plane in back $(80 \times 50 \mathrm{~mm})$. Fig. shows Geometry of the proposed LTCC UWB chip antenna and 19 layers of chip antenna where top layer is rectangular metal plate and $10^{\text {th }}$ plate is a diamond shaped metal plate. UWB chip antenna is fed using microstrip line printed on the PCB substrate's top side. Antenna has good gain with values $2.43-3.44 \mathrm{dBi}$. Bandwidth is from 2.39 to $7.75 \mathrm{GHz}$ and has three separate wide-impedance bandwidths. It has compact structure, which makes it easy to fit in any housing of mobile, thus leading to an internal UWB antenna [13].

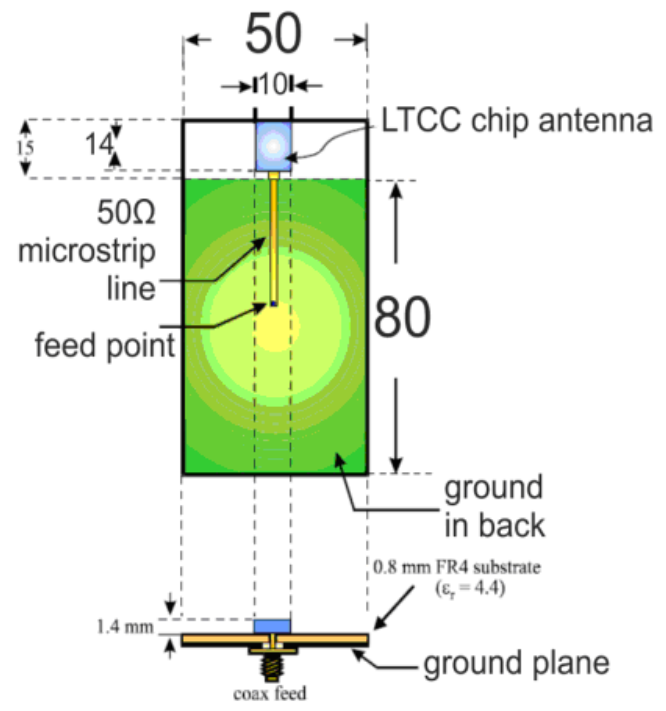

Fig. 7 UWB chip antenna for mobile applications

\subsection{CPW-Fed square octal shaped UWB antenna}

Antenna depicted in Fig. 5 has been designed on FR4 rectangular substrate. FR4 substrate has length $100 \mathrm{~mm}$ and thicknesses $1.53 \mathrm{~mm}$. The radiation pattern is nearly omnidirectional. The main feature of proposed antenna is double frequency band. The first band starts on 0.62 and stops at $1.657 \mathrm{GHz}$. The second band starts from 2.86 $\mathrm{GHz}$ and stops at $14.38 \mathrm{GHz}$. The antenna has ultra wide operating bandwidth at higher frequencies. The Fig. 8 shows ground plane and radiation patch of antenna. They are at the same side of FR4 substrate. The rotated square octal shaped fractal has been designed using a simple iterative pattern. In this antenna were used overall five iterations [14]. The gain of antenna is 1.19 to $4.18 \mathrm{dBi}$ and it was designed for UWB systems, positioning system, microwave imaging and radar applications [15].

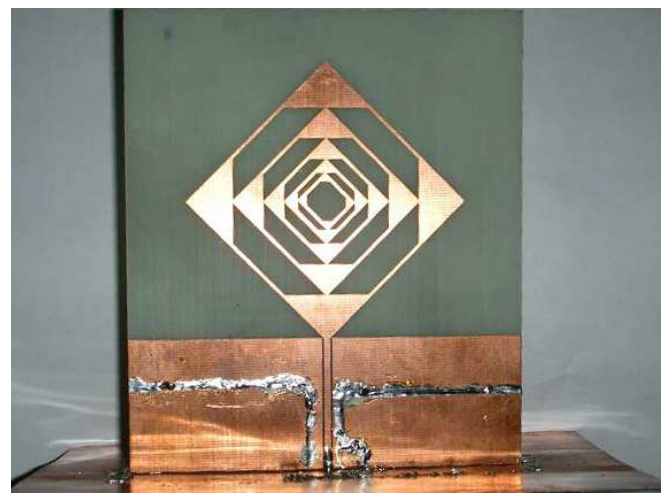

Fig. 8 UWB fractal antenna with five iterations [15]

Table 1

\begin{tabular}{|c|c|c|c|c|c|}
\hline Type of antenna & $\begin{array}{c}\text { Bandwidth } \\
(\mathrm{GHz})\end{array}$ & Gain (dBi) & $\begin{array}{c}\text { Dimensions } \\
(\mathrm{mm})\end{array}$ & $\begin{array}{l}\text { Dielectric } \\
\text { substrate }\end{array}$ & Features \\
\hline Monopole-like slot UWB antenna & $3.1-11.9$ & 4 & $\begin{array}{c}25 \times 25 \times \\
0.58\end{array}$ & LTCC & $\begin{array}{l}\text { constant gain } \\
\text { and group delay }\end{array}$ \\
\hline Multilayer UWB monopole antenna & $3.6-10.6$ & 1.45 & $\begin{array}{c}20.748 \times \\
11.091 \times 1.14 \\
\end{array}$ & LTCC & $\begin{array}{c}2 \text { antennas } \\
\text { combined to } 1\end{array}$ \\
\hline Chip antenna for UWB radios & $3.75-10.45$ & $-2-2.3$ & $17 \times 8 \times 0.8$ & $\begin{array}{l}\text { LTCC by } \\
\text { Ferro }\end{array}$ & UWB radios \\
\hline $\begin{array}{l}\text { UWB chip antenna for mobile } \\
\text { applications }\end{array}$ & $2.39-7.75$ & $2.43-3.44$ & $10 \times 14 \times 1.4$ & $\begin{array}{l}\text { LTCC + } \\
\text { FR4 }\end{array}$ & $\begin{array}{c}3 \text { wide - } \\
\text { impedance } \\
\text { bandwidth }\end{array}$ \\
\hline $\begin{array}{l}\text { CPW-Fed square octal shaped UWB } \\
\text { antenna }\end{array}$ & $\frac{0.62-1.657 ;}{2.86-14.38}$ & $1.19-4.18$ & $\begin{array}{c}100 \times 100 \times \\
1.53\end{array}$ & FR4 & $\begin{array}{l}2 \text { frequency } \\
\text { bands }\end{array}$ \\
\hline
\end{tabular}

\section{CONCLUSIONS}

In this article, there are presented the evolution of ultra-wideband antennas and a brief overview of antennas, which are practically realized. The Table 1 shows practical realization of antennas and their bandwidth, gain, dimensions, and main features. The greatest bandwidth is obtained by CPW-Fed square-octal shaped UWB antenna
(Fig. 8). This antenna is made of physically large PCB substrate. It is thought that this attribute is a disadvantage. The gain of all discussed antennas is suitable for use in UWB systems. As the last of the mentioned key features, there are the dimensions of the antenna. All of the smallest dimensions are obtained with use of LTCC technology. In addition to other good features of LTCC, it includes a flexibility of material and the ability to create multilayer 
and 3-dimensional structure. We assume that the fractal geometry, LTCC technology and used PCB technology as feed line will be beneficial for usage in design of UWB antenna. The combination of good features of assessed antennas (marked in the table) should be considered and examined in the other works. It will be helpful in design of antenna, which is suitable for UWB radar applications.

\section{ACKNOWLEDGMENTS}

This work was supported by the Scientific Grant Agency of the Ministry of Education, science, research and sport of the Slovak Republic under the contract No. 1/0563/13 and by the Slovak Research and Development Agency under the contract No. APVV-0404-12.

\section{REFERENCES}

[1] JANGID, S. - KUMAR, M.: "Compact Planar UWB Patch Antenna with Integrated Bandpass Filter \& Band Notched Characteristics," Communication Systems and Network Technologies (CSNT), 2012 International Conference, pp.15, 19, 11-13 May 2012.

[2] StRATTON, J. A. - CHU, L. J.: Journal of Applied Physics, March, 1941.

[3] SCHELKUNOFF, S. A.: "Electromagnetic Waves," Van Nostrand, 1943.

[4] Radio Research Laboratory (U.S.), "Very Highfrequency Techniques," McGraw Hill, New York, 1947, pp. 1-25, Chap 1

[5] DYSON, J. D.: "The Equiangular Spiral Antenna," IRE Trans. Antennas \& Propagation, vol. AP-7, pp. 181-187, April 1959.

[6] DUHAMEL, R. H.: "Dual Polarized Sinuous Antennas," U.S. Patent 4,658,262, April 14, 1987.

[7] BYRON, E. V.: "A new flush-mounted antenna element for phased array application," in Proc. Phased-Array Antenna Symp., 1970, pp. 187-192.

[8] VOLAKIS, J. L. - CHEN, C. C. - FUJiMOTO, K.: „Small antennas - Miniaturization techniques \& applications“" ISBN 978-0-07-162553-1, 2010.

[9] STUTZMAN, W. L. - THIELE, G. A.: „Antena Theory and Design - third edition" ISBN 978-047057664-9, 2012.

[10] QING, X. - CHEN, Z. N.: "Monopole-like slot UWB antenna on LTCC," Ultra-Wideband, 2008, ICUWB 2008, IEEE International Conference on, vol. 2, pp. 121,124, 10-12 Sept. 2008.
[11] ZHANG, Y. Q. - GUO, Y. X. - LEONG, M. S.: "A Novel Multilayer UWB Antenna on LTCC," Antennas and Propagation, IEEE Transactions on , vol. 58, no. 9, pp. 3013,3019, Sept. 2010.

[12] SUN, M. - ZHANG, Y.: "A Chip Antenna in LTCC for UWB Radios," Antennas and Propagation, IEEE Transactions on, vol. 56, no. 4, pp. 1177,1180, April 2008.

[13] WU, C. Y. - TANG, C. L. - CHEN, A. C.: "UWB chip antenna design using LTCC multilayer technology for mobile applications," Microwave Conference Proceedings, 2005, APMC 2005, AsiaPacific Conference Proceedings, vol. 3, pp. 3, pp. 47, Dec. 2005.

[14] HAJI-HASHEMI, M. R. - MIR-MOHAMMAD SADEGHI, M. - MOGHTADAI, V. M.:'Spacefilling patch antennas with CPW feed," Progress in Electromagnetic Research Symposium, March 2629, 2009.

[15] KUMAR, R. - SHINDE, J. P. - SHINDE, P. N. UPLANE, M. D.: "On the design of CPW-fed square octal shaped fractal UWB antenna," Applied Electromagnetics Conference (AEMC), 2009, pp. 1,3, 14-16 Dec. 2009.

Received March 30, 2014, accepted June 15, 2014

\section{BIOGRAPHIES}

Ján Schneider (Ing.) received Ing. (MSc.) degree in 2013 at the Department of Technology in Electronics, Faculty of Electrical Engineering and Informatics at the Technical University in Košice. His thesis title was "Vibration test in electronics". Since September 2013 he has been at Department of Electronics and Multimedia Communications at Technical University in Košice as PhD. student. His dissertation thesis is "Passive elements of UWB radar based on LTCC technology".

Ján Gamec graduated (MSc) in 1985 with distinction at the Department of Radioelectronics of the Faculty of Electrical Engineering and Informatics at Technical University in Košice. He defended his $\mathrm{PhD}$ in the field of radioelectronics in 1995. Currently he is an associated professor at the Department of Electronics and Multimedia Communications of the Faculty of Electrical Engineering and Informatics at Technical University in Košice. His main area of scientific research is digital image processing and UWB radar signal processing. 